\title{
Research on Test Method of Foundation Bed Coefficient in Nanjing Soft Soil Area
}

\author{
Min Zhang $\mathbb{D}^{1}$ and Tao Qiu $\mathbb{D}^{2}$ \\ ${ }^{1}$ Department of Geotechnical Engineering College of Civil Engineering, Tongji University, Shanghai 200092, China \\ ${ }^{2}$ School of Civil Engineering, Nanjing Forestry University, Nanjing, Jiangsu Province 210037, China \\ Correspondence should be addressed to Tao Qiu; qt@njfu.edu.cn
}

Received 19 March 2021; Revised 9 October 2021; Accepted 10 November 2021; Published 30 November 2021

Academic Editor: Nasar Golsanami

Copyright (c) 2021 Min Zhang and Tao Qiu. This is an open access article distributed under the Creative Commons Attribution License, which permits unrestricted use, distribution, and reproduction in any medium, provided the original work is properly cited.

\begin{abstract}
Relying on the geotechnical engineering survey project of Nanjing Lukou Airport, this research adopts the method of combining in situ and indoor testing to analyze the coefficient of soil foundation under different conditions (flow plastic, plastic, and soft plastic). Based on the differences in test results, in situ and indoor test methods appropriate for the benchmark bed coefficient of Nanjing soft soil area are proposed. Research findings depicted that the bed coefficients obtained by different methods are not similar; therefore, if the data obtained by different methods need to be compared and analyzed, they have to be unified as $K_{30}$. Simultaneously, in the indoor test, this study compared the foundation bed coefficient obtained by the consolidation method, the improved $K_{0}$ instrument consolidation method, and the triaxial method. Results revealed that the improved $K_{0}$ instrument consolidation method can better realize the test of the soil foundation coefficient. This study can provide a reference for geotechnical investigation and design of soft soil in the study area.
\end{abstract}

\section{Introduction}

The foundation bed coefficient is an important parameter in the design of underground engineering such as foundation pit enclosure and underground rail transit; therefore, it is critical to determine its value [1-5]. As an inherent mechanical property index, the coefficient of the foundation bed is determined by the properties of soil. Regarding the experiment of the foundation bed coefficient and the discussion of the value method, a lot of experimental research work has been carried out. For example, Sandu et al. [6] deduced the calculation of the lateral foundation bed reaction coefficient based on the working mechanism of the flat shovel side expansion instrument formula. Corrêa-Silva et al. [7] combined the geotechnical survey of Wuhan light rail and compared the foundation bed coefficient consolidation method and the triaxial method. Shen et al. [8] used a flat shovel side dilatometer to test and study the horizontal bed coefficient of coastal sedimentary soft soils. Based on indoor consolidation test and triaxial test, Wang et al. [9] used the size correction empirical formula to correct the bed coefficient directly determined by the indoor test. Ren et al. [10] deduced the calculation formula of the bed coefficient with the compressive modulus as a known parameter and compared it with the empirical value given by the specification. At present, in geotechnical engineering surveys, in situ tests such as $K_{30}$ plate load test, spiral plate load test, side pressure test, and flat shovel side expansion test as well as indoor consolidation method and triaxial method are mainly employed to test the bed coefficient [11-18]. However, due to the influence of test equipment and sample size, the values obtained by different test methods are quite different [19-23]. In actual work, the Terzaghi correction formula is often used to correct the diameter of the $K_{30}$ flat load plate diameter as the standard [24-28]. Finally, the value of the soil foundation bed coefficient is proposed in conjunction with the experience value.

Previous research indicates that the bed coefficient was primarily used for comparing the flat shovel side expansion test, indoor consolidation, and triaxial test [29-32]. It was rarely verified with the benchmark value of the $K_{30}$ test, and there was no related test using the $K_{0}$ instrument. To 
compensate for these shortcomings, this article analyzes various test methods and improves the limitation that the previous $K_{30}$ device can only obtain the vertical bed coefficient and realizes the test of the horizontal bed coefficient by this device, based on the geotechnical engineering investigation project of Nanjing Lukou Airport. At the same time, the $K_{0}$ instrument is modified and developed and then compared with other indoor tests (such as indoor consolidation method and triaxial method). The improved $K_{0}$ consolidation method can better realize the test of soil base coefficient. An in situ test and laboratory test method suitable for the benchmark subgrade coefficient in Nanjing soft soil area is proposed based on the analysis data of Nanjing soft soil in situ test and laboratory test and relying on the related theory of soil mechanics. This research can be used to guide geotechnical investigations and foundation design in the Nanjing soft soil area.

\section{Engineering Geological Conditions}

As shown in Figure 1, Nanjing is located in the east of China, the lower reaches of the Yangtze River. It is located along the Yangtze River and has a developed water network, which makes the soft soil of lagoons and river alluvial deposits widely distributed. These soft soil layers are usually mud and silt soil, which are characterized by high water content, low strength, high compressibility, poor permeability, uneven soil quality, and great differences between regions. The test site of this study is located in Lukou International Airport in Jiangning District, southeast Nanjing. The test site has a single topography and is a coastal alluvial plain. The sedimentary types are mainly Quaternary marine soft soil layers. According to the survey report combined with the on-site drilling situation, the foundation soil within the survey depth range is divided into 7 engineering geological layers from top to bottom with regard to the geological age. Table 1 depicts the distribution and physical and mechanical properties of each soil layer.

In this study, the upper plastic (hard shell layer), lower flow plastic, soft plastic, and plastic clay soil foundation coefficients were tested and analyzed in conjunction with the engineering geological conditions and the physical and mechanical properties of the soil.

In Table $1, \omega$ is water content, $\gamma$ is the gravity of soil, $e_{0}$ is the pore ratio, $I_{\mathrm{P}}$ is the plasticity index, $I_{\mathrm{L}}$ is the liquid index, and $E_{\mathrm{s} 1-2}$ is the compression modulus.

\section{Test Plan Design}

Due to the geotechnical engineering conditions of the soil in the study area, in situ test methods such as $K_{30}$ plate load test, flat shovel side expansion test, indoor consolidation method, improved $K_{0}$ instrument consolidation method, and triaxial method were adopted. In combination, test and analysis were carried out on soils in various states (flow plastic, plastic, and soft plastic) widely distributed in Nanjing.

\subsection{In Situ Test}

3.1.1. $K_{30}$ Load Test. In Chinese rail transit engineering and railway engineering, the $K_{30}$ load test is often used as a direct method to determine the coefficient of the foundation soil, which is based on the load test results under the condition of a $30 \mathrm{~cm}$ diameter circular plate. As shown in Figure 2, 6 test points are arranged near the corresponding in situ test and sampling holes in the test site. The $K_{30}$ plate load tester is used to plasticize the upper part of the test depth. Clay (hard shell layer) is tested for bed coefficient. This test uses a balance beam to pressurize, a truck to provide a reaction force, and an improved back wall to provide a reaction force in the horizontal bed coefficient test.

During the test, the load plate is placed on the flat test point, and the truck matching the test is driven to a place less than $1 \mathrm{~m}$ away from the test site, making the rear beam of the truck located directly above the load plate. The jack is placed on the load plate and the measuring bridge is installed, and the jackscrew is turned so that it is in contact with the truck reaction beam. Then, the dial indicator is also installed making the dial indicator rod fall vertically to the load measuring point. The increment of $0.04 \mathrm{MPa}$ was applied step by step to record the amount of subsidence of each stage of load. When the load intensity exceeded the estimated actual contact pressure in situ or reached the yield point of the foundation, the test would stop.

3.1.2. Side Expansion Test of a Flat Shovel. In this test, the ETU-G1-type flat shovel side swelling tester is used and two test points are arranged to test the horizontal subgrade coefficients of the flowing plastic, soft plastic, and plastic soil on the hard shell layer and its lower part. As depicted in Figure 3, during the test, the flat shovel side expansion test probe is pressed into the soil with TMU-9C static penetration testing equipment. After achieving the predetermined depth, air is injected to expand the steel membrane on the flat shovel probe laterally, and then, the pressure values of lateral expansion of the membrane at different distances were measured, respectively $(0.05 \mathrm{~mm}$ and $1.10 \mathrm{~mm})$. Finally, the physical and mechanical properties of the foundation soil are calculated using a formula based on the relationship between the measured pressure and membrane deformation [33-54].

\subsection{Indoor Test}

3.2.1. Test Plan. Indoor tests on thin-walled soil samples collected on-site are conducted using the consolidation method, improved $K_{0}$ instrument consolidation method, and triaxial method.

3.2.2. Test Method. Indoor tests were conducted by consolidation method, $K_{0}$ instrument consolidation method, and indoor triaxial test, and test samples were prepared for each method in advance; the specific sample size of the tests can be seen in Table 2 .

(1) Consolidation Method. In the test, a ring knife with an inner diameter of $61.8 \mathrm{~mm}$ and a height of $15 \mathrm{~mm}$ was used to take soil samples and placed them into the WG-type consolidation instrument (see Figure 4(a)); both ends of the soil sample are pasted with filter paper. Pressure guide rings, plates, and directional steel balls were installed on the soil 

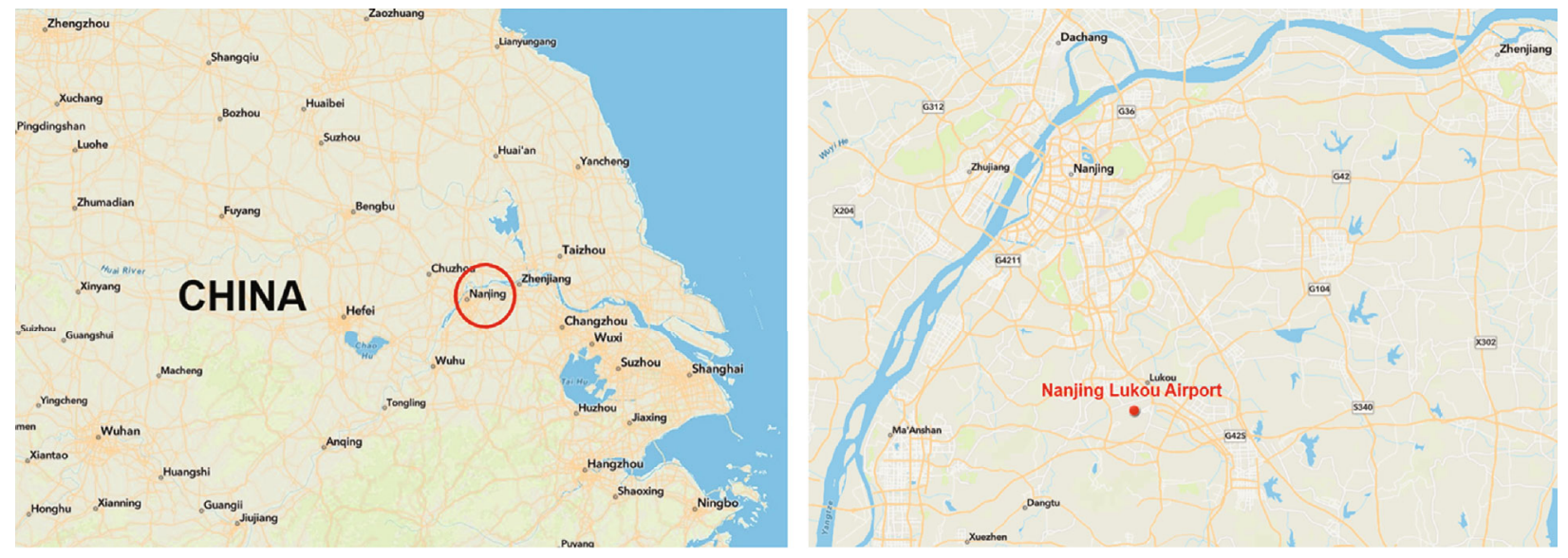

FIgURE 1: Geographical location of the test site.

TABle 1: Foundation soil distribution and physical and mechanical properties index.

\begin{tabular}{|c|c|c|c|c|c|c|c|c|c|}
\hline Layer number & Lithology name & Soil thickness (m) & Soft plastic & $\omega(\%)$ & $\gamma\left(\mathrm{KN} / \mathrm{m}^{3}\right)$ & $e_{0}$ & $I_{\mathrm{P}}$ & $I_{\mathrm{L}}$ & $E_{\mathrm{s} 1-2}(\mathrm{MPa})$ \\
\hline 1 & Fill soil & $0.4-0.6$ & I & I & l & I & I & I & I \\
\hline 2 & Clay & $0.7-2.6$ & Plastic & 28.3 & 16.3 & 1.21 & 16.98 & 0.52 & 3.63 \\
\hline 3 & Silty powdered clay & $4.0-11.9$ & Flow plastic & 41.3 & 15.2 & 1.12 & 17.32 & 1.23 & 2.65 \\
\hline 4 & Silty clay & $5.8-12.6$ & Flow plastic & 40.6 & 15.9 & 1.35 & 14.36 & 1.13 & 1.69 \\
\hline 5 & Clay & $4.9-9.8$ & Soft plastic & 47.3 & 15.4 & 1.24 & 18.65 & 1.03 & 1.98 \\
\hline 6 & Powdered clay & $2-4.6$ & Plastic & 29.8 & 17.2 & 0.61 & 19.32 & 0.65 & 1.75 \\
\hline 7 & Round gravel & $>5.3$ & Compact & I & I & I & l & l & l \\
\hline
\end{tabular}

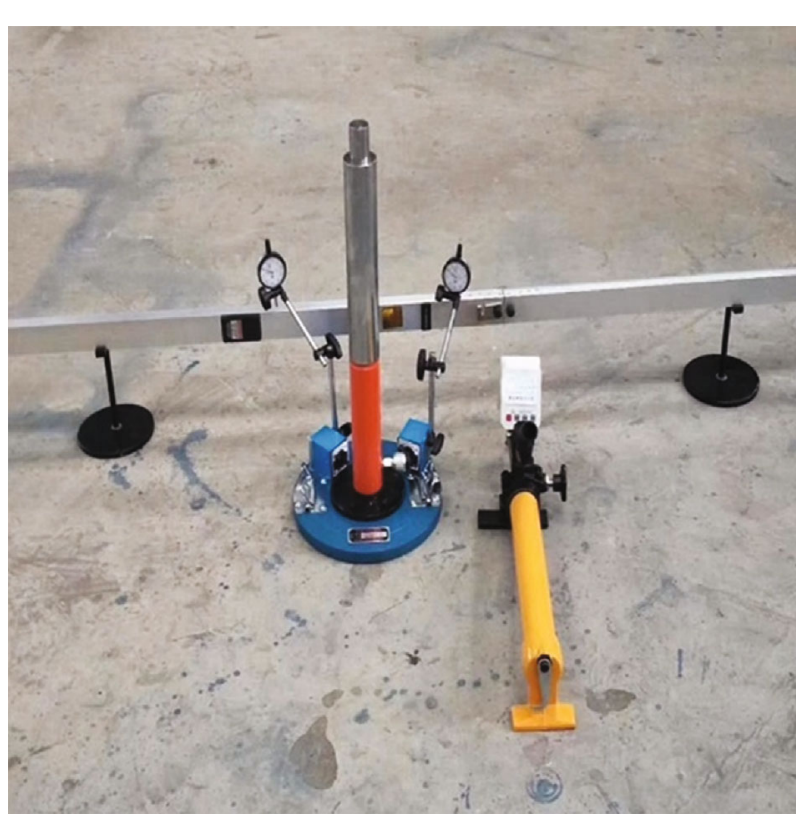

FIgURE 2: $K_{30}$ plate load tester.

sample, and the joints of each were checked whether the part-turn is flexible and then balances the pressurized part. After the cross beam contacts with the ball column, the piston rod and the micrometer were installed and adjusted to zero. The vertical pressure level is $12.5,25,50,100,200$, and $400 \mathrm{kPa}$, and the degree of each level of load is recorded after 10 minutes; the reading is accurate to $0.01 \mathrm{~mm}$. The curve corresponding to $25 \sim 50 \mathrm{kPa}$ is used as the value interval of the bed coefficient.

(2) $K_{0}$ Instrument Consolidation Method. As shown in Figure 4(b), the container of the ETU-G1 $K_{0}$ instrument is used to replace the consolidation container of the horizontal bar consolidation instrument, the pressure frame matching the $K_{0}$ instrument container is reassembled, and the displacement sensor for measuring displacement is mounted on the pressure frame to perform the basic indoor test of bed coefficient.

Before the $K_{0}$ consolidation instrument was used, air bubbles in the closed chamber and side pressure system were removed, and the sealing of the closed chamber and pipeline system was checked. The undisturbed soil sample was cut with a ring knife with an inner diameter of $61.8 \mathrm{~mm}$ and a height of $40 \mathrm{~mm}$ and pushed into the $K_{0}$ consolidation instrument's container. The upper side pressure sensor was installed, and then, air bubbles in the compression chamber and piping system were gushed out. Also, the pressure frame and displacement sensor are installed. A prepressure of $1 \mathrm{kPa}$ was applied to make contact between the sample and the upper and lower parts of the instrument, and the displacement sensor was adjusted to an appropriate position. The acquisition and processing software were opened to configure the test parameters 


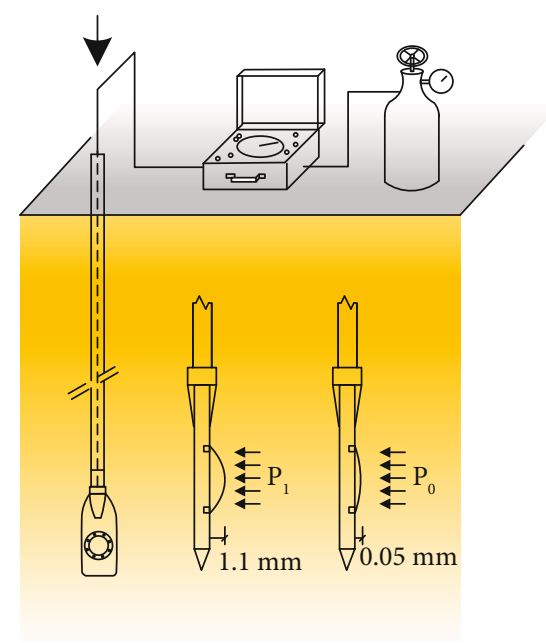

Figure 3: Side expansion test of a flat shovel.

TABLE 2: Sample size.

\begin{tabular}{lccc}
\hline Testing method & $\begin{array}{c}\text { Height } \\
(\mathrm{mm})\end{array}$ & $\begin{array}{c}\text { Radius } \\
(\mathrm{mm})\end{array}$ & $\begin{array}{c}\text { The ratio of height to } \\
\text { radius }\end{array}$ \\
\hline $\begin{array}{l}\text { Consolidation } \\
\text { method }\end{array}$ & 15 & 25.5 & 0.59 \\
$\begin{array}{l}K_{0} \text { consolidation } \\
\text { method }\end{array}$ & 30 & 25.5 & 1.18 \\
\begin{tabular}{l} 
Triaxial method \\
\hline
\end{tabular} & 45 & 17.3 & 2.60 \\
\hline
\end{tabular}

(pressure levels, data collection time, etc.). Vertical pressures of $25,50,75,100,150,200,300$, and $400 \mathrm{kPa}$ were applied, respectively, till the end of the test. The $\mathrm{P}-\mathrm{S}$ curve of the indoor test is close to a straight line at the initial stage, and the secant modulus is used to estimate the bed coefficient at the soil sample sinking amount of $1.25 \mathrm{~mm}$.

(3) Indoor Triaxial Test. As shown in Figure 4(c), the triaxial test adopts a cylinder sample with a diameter of $25.5 \mathrm{~mm}$ and a height of $45 \mathrm{~mm}$ for testing. Firstly, the sample is loaded into the vacuum saturation device for saturation, and then, pressure is applied on the three coordinate directions of the sample in space, carrying out a consolidation drainage test (CD) at the state of $K_{0}$. The stress path is taken as $\Delta \sigma_{3} / \Delta \sigma_{1}=0,0.2,0.3$, and 0.3 independently, until the specimen is destroyed. Finally, take the secant modulus at $\Delta \sigma_{3} / \Delta \sigma_{1}=0.3$ and deformation $S=1.32 \mathrm{~mm}$ (strain $1.76 \%$ ) as the bed coefficient.

\section{Test Results and Discussion}

4.1. Comparative Analysis of Test Data. According to different test schemes, the numerical values obtained are analyzed separately according to the depth of the soil sample and its physical state (plasticity, flow plasticity, soft plasticity, and plasticity), and the numerical analysis of the bed coefficient adopts the mean value. The statistics of actual measured values of soil foundation bed coefficient under each test method are shown in Table 3.
It can be seen from Table 3 that there are large differences in the coefficient of foundation soil under the same geological conditions, and the ratio of the maximum value to the minimum value is 1.5 to 5.3. Take the following plastic silty clay test results as an example. The vertical bed coefficient obtained by different test methods is in the range of 94.3 195.3 MPa/m, and the difference between the maximum value and the minimum value is nearly 2.1 times. Comparing the empirical value range from 18 to $40 \mathrm{MPa} / \mathrm{m}$, the results are also several times different. As a result, if a unified value standard is not used, the results of various test methods cannot be directly applied in design.

4.2. Diameter Correction. Terzaghi believes that the bed factor is related to the size of the load board. Therefore, the bed factor directly measured by load boards of different sizes and indoor samples is corrected to the on-site $K_{30}$ value ( $D=30 \mathrm{~cm}$ load board). It can be modified according to the following formula:

To sandy soils,

$$
K_{30}=\frac{(2 B)^{2}}{(B+0.3)^{2}} K
$$

To cohesive soil,

$$
K_{30}=\frac{B}{0.3} K
$$

where $B$ is the diameter or width of the load plate and $K$ is the base bed coefficient value measured directly.

Considering the influence of the size effect, after diameter correction, the correction values of soil bed coefficients in different states are listed in Table 3. The in situ test is carried out on the plastic-like hard crust that is common on the surface of the soft soil area in Nanjing. Based on the most direct and effective $K_{30}$ plate load test, the vertical base bed coefficient obtained is greater than the indoor test method after the diameter correction. The value is consistent with the in situ test value of the flat shovel side expansion and is close to the upper limit of the empirical value; the indoor test value is significantly smaller than the in situ test value. The analysis shows that the value of the base bed coefficient after the diameter correction tends to be the same for the in situ test, but the value obtained after the diameter correction differs significantly between the in situ test and the indoor test.

The bed coefficients obtained by the indoor triaxial method after diameter correction are low, which is inconsistent with the physical and mechanical properties of the soil, mainly because the sample size employed in the indoor triaxial method is $39.1 \mathrm{~mm} \times 80 \mathrm{~mm}$. Although the height is relatively large, its diameter is relatively small. Due to the limitation of the engineering characteristics of the soft soil, the disturbance is relatively large when the sample is made indoors, and the value is relatively low; for the clayey soil in the plastic state, the physical and mechanical properties of face sedimentary soil are better than the upper hard crust layer due to the lower land, so its value is slightly larger than it, but the values of both are generally smaller than the 


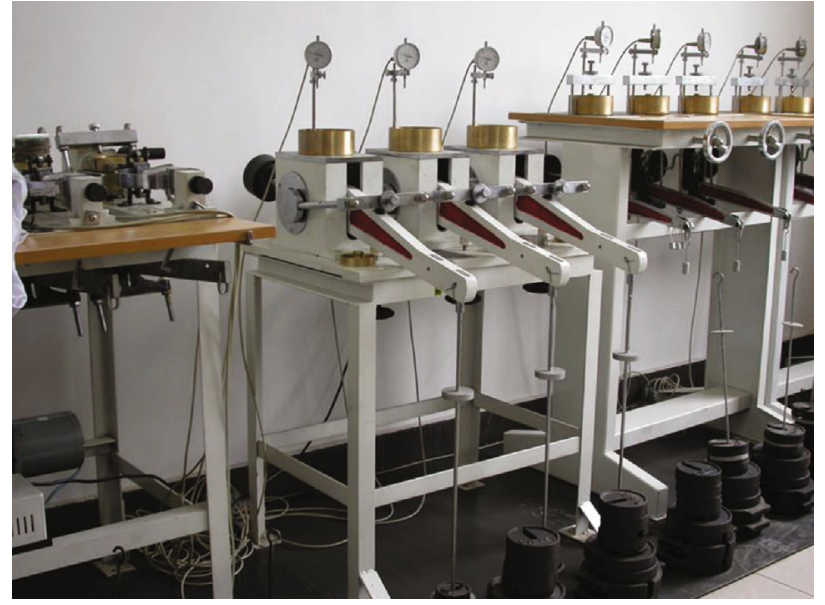

(a) Consolidation instrument

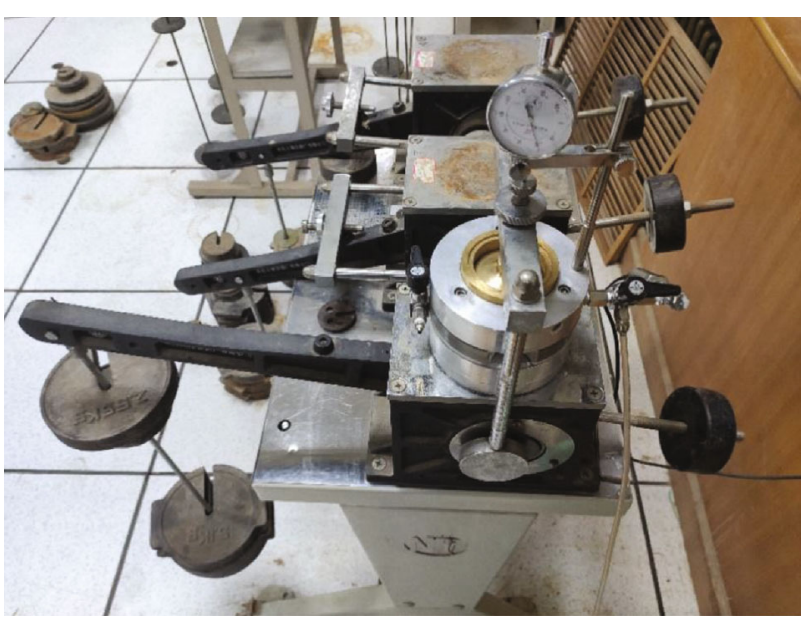

(b) $K_{0}$ instrument

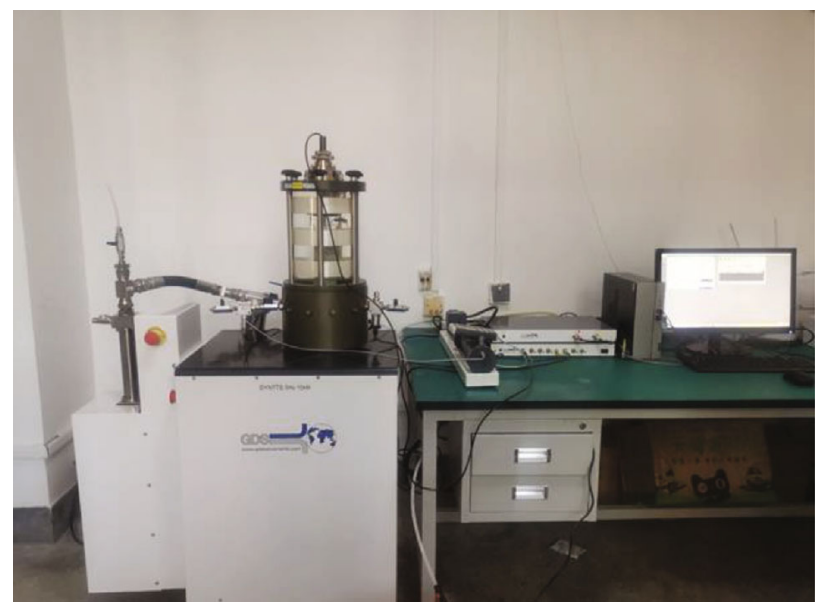

(c) Triaxial instrument

FIgURE 4: Indoor test apparatus.

TABLE 3: Measured and corrected values of bed coefficient.

\begin{tabular}{|c|c|c|c|c|c|c|c|c|}
\hline \multirow{2}{*}{ Testing method } & \multicolumn{2}{|c|}{$\begin{array}{c}\text { Plastic } \\
\text { (hard shell layer) }\end{array}$} & \multicolumn{2}{|c|}{ Flow molding } & \multicolumn{2}{|c|}{ Soft plastic } & \multicolumn{2}{|c|}{ Plastic } \\
\hline & Vertical & Level & Vertical & $\begin{array}{l}\text { Level } \\
(\mathrm{M}\end{array}$ & $\begin{array}{l}\text { Vertical } \\
\mathrm{m})\end{array}$ & Level & Vertical & Level \\
\hline$K_{30}$ & 30.1 & 23.6 & l & l & l & l & l & l \\
\hline Flat shovel side expansion method & I & 123.2 & I & 62.1 & I & 113.6 & I & 150.3 \\
\hline$K_{0}$ consolidation method & 69.8 & 71.2 & 42.3 & 40.2 & 60.2 & 56.3 & 80.3 & 80.3 \\
\hline Consolidation method & 165.3 & l & 68.2 & l & 125.5 & l & 180.5 & l \\
\hline Triaxial method & 62.3 & 75.6 & 15.3 & 20.3 & 21.3 & 25.1 & 90.2 & 96.5 \\
\hline Maximum/minimum (measured value) & 3.6 & 5.3 & 2.3 & 1.8 & 3.5 & 3.5 & 1.8 & 1.5 \\
\hline Specification recommended value & $12-22$ & $10-26$ & $2-11$ & $2-8$ & $6-18$ & $10-21$ & $15-38$ & $18-40$ \\
\hline
\end{tabular}

empirical value, which is also related to the degree of artificial disturbance in the sample preparation process.

Table 4 depicts the vertical bed coefficients obtained by the $K_{0}$ instrument consolidation method and consolidation method after the diameter correction in different conditions. Also, for the same geological conditions, the ratio of the vertical bed coefficients obtained by the two consolidation methods is 1.2 to 2.46 , which is close to 2.5 , and its value is app ratio $1 / 2$ relation which is approximately inversely proportional to the sample heights hip. The analysis demonstrates that diameter correction of the bed coefficients obtained by the two consolidation methods is impossible, and the effect of sample height on test results should be considered concurrently. 
TABLE 4: Comparison of vertical bed coefficients of different methods.

\begin{tabular}{lccccc}
\hline Testing method & Plastic & Flow molding & Soft plastic & Plastic & Sample size $(\mathrm{mm})$ \\
\hline Consolidation method & 32.1 & 14.2 & 21.3 & 34.63 & $15 * 45.5$ \\
$K_{0}$ consolidation method & 12.3 & 9.3 & 16.4 & 15.24 & $30 * 45.5$ \\
Triaxial method & 1.85 & 1.2 & 1.85 & 2.46 & $/$ \\
\hline
\end{tabular}

\section{Conclusion}

Relying on the geotechnical engineering survey project of Nanjing Lukou Airport, this study adopts the method of combining on-site in situ testing and indoor testing to test and analyze the coefficient of soil foundation under different conditions (flow plastic, plastic, and soft plastic). According to related theories, the standard of the base bed coefficient is compared and analyzed, and the in situ test and indoor test methods suitable for the benchmark bed coefficient of the Nanjing soft soil area were proposed.

It is found that the bed coefficients (vertical, horizontal) obtained by different test methods, due to the influence of the size effect, the bed coefficients of the same foundation soil are very different, so they must be unified to $K_{30}$. Secondly, in the indoor test, the improved $K_{0}$ instrument consolidation method can better realize the test of the soil foundation coefficient. Finally, due to the limitation of the sample size, the triaxial test is easy to cause damage to the soft soil during the sample preparation process. Larger disturbances result in a significantly lower value of the base bed coefficient, so the soft soil should be avoided as much as possible when making samples.

\section{Data Availability}

The data are generated from experiments and can be available from the corresponding author upon request.

\section{Conflicts of Interest}

The authors declare that there are no conflicts of interest regarding the publication of this paper.

\section{Authors' Contributions}

Zhang Min carried out the experiments, analyzed the results, conducted the theoretical explanations, and wrote the manuscript. Qiu Tao provided constructive guidance for the thesis, and we revised the thesis in writing.

\section{Acknowledgments}

The authors would like to express appreciation to the Faculty of Civil Engineering, Nanjing Forestry University, for providing the laboratory.

\section{References}

[1] D. Chandran and P. Anbazhagan, "2D nonlinear site response analysis of typical stiff and soft soil sites at shallow bedrock region with low to medium seismicity," Journal of Applied Geophysics, vol. 179, 2020.
[2] R. He, C. Sandu, and J. E. Osorio, "Systematic tests for study of tire tractive performance on soft soil: Part II - parameterization of terramechanics model and tire model," Journal of Terramechanics, vol. 85, pp. 77-88, 2019.

[3] T. T. Nguyen and B. Indraratna, "Micro-CT scanning to examine soil clogging behavior of natural fiber drains," Journal of Geotechnical and Geoenvironmental Engineering, vol. 145, no. 9,2019

[4] W. Wang, C. Zhang, N. Li, F. Tao, and K. Yao, "Characterisation of nano magnesia-cement-reinforced seashore soft soil by direct-shear test," Marine Georesources \& Geotechnology, vol. 37, no. 8, pp. 989-998, 2019.

[5] K. Zhang, Q. Liu, K. Jin, L. Wang, Y. Cheng, and Q. Tu, "Influence of overlying caprock on coalbed methane migration in the Xutuan coal mine, Huaibei coalfield, China: a conceptional analysis on caprock sealability," Geofluids, vol. 2019, Article ID 9874168, 17 pages, 2019.

[6] C. Sandu, S. Taheri, S. Taheri, and D. Gorsich, "Hybrid soft soil tire model (HSSTM). Part II: tire-terrain interaction," Journal of Terramechanics, vol. 86, pp. 15-29, 2019.

[7] M. Corrêa-Silva, T. Miranda, M. Rouainia, N. Araújo, S. Glendinning, and N. Cristelo, "Geomechanical behaviour of a soft soil stabilised with alkali-activated blast- furnace slags," Journal of Cleaner Production, vol. 267, 2020.

[8] S.-L. Shen, P. G. Atangana Njock, A. Zhou, and H.-M. Lyu, "Dynamic prediction of jet grouted column diameter in soft soil using Bi-LSTM deep learning," Acta Geotechnica, vol. 16, no. 1, pp. 303-315, 2021.

[9] H. Wang, C. F. Leung, J. Yu, and M. Huang, "Axial response of short pile due to tunnelling-induced soil movement in soft clay," International Journal of Physical Modelling in Geotechnics, vol. 20, no. 2, pp. 71-82, 2020.

[10] Y. Ren, Q. Yang, Y. Wang, and W. Zhao, "Experimental study on the undrained shear strength of deep-sea soft soil using improved T-bar penetrometer," Marine Georesources \& Geotechnology, vol. 38, no. 10, pp. 1199-1208, 2020.

[11] S. Getzin, H. Yizhaq, M. Muñoz-Rojas, K. Wiegand, and T.E. Erickson, "A multi-scale study of Australian fairy circles using soil excavations and drone-based image analysis," Ecosphere, vol. 10, no. 2, 2019.

[12] J. He, Z. X. Li, X. Wang, and X.-K. Shi, "Durability of soft soil treated with soda residue and ground granulated blast furnace slag in a soaking environment," Journal of Materials in Civil Engineering, vol. 32, no. 3, 2020.

[13] J. Xu, Y. Wang, C. Yan et al., "Lifecycle health monitoring and assessment system of soft soil subgrade for expressways in China," Journal of Cleaner Production, vol. 235, pp. 138-145, 2019.

[14] H. Bayesteh and R. Mansouriboroujeni, "Mechanisms of settlement of a rubble mound breakwater on a soft soil in tidal flats," Marine Georesources \& Geotechnology, vol. 38, no. 10, pp. 1163-1176, 2020. 
[15] W. Feng, J. Yin, W. Chen, and P. Wu, "Development and performance of new simplified method for soft soil with creep under multi-staged loading," Marine Georesources \& Geotechnology, vol. 39, no. 4, pp. 431-447, 2021.

[16] Z. Ding, X. Zhang, X. Yin, and J. Jiang, "Analysis of the influence of soft soil grouting on the metro tunnel based on field measurement," Engineering Computations, vol. 36, no. 5, pp. 1522-1541, 2019.

[17] H. Y. Sun, J. Wang, D. F. Wang, Y. Yu, and Z. L. Wei, “Optimal design of prefabricated vertical drain-improved soft ground considering uncertainties of soil parameters," Journal of Zhejiang University-Science A, vol. 21, no. 1, pp. 15-28, 2020.

[18] X. Yang, G. Jin, M. Huang, and K. Tang, "Study on the surface particle distribution characteristics of silt with different moisture content," Arabian Journal of Geosciences, vol. 13, no. 1, pp. 1-10, 2020.

[19] F. Q. Chen, L. Lin, and J. Wang, "Energy method as solution for deformation of geosynthetic-reinforced embankment on Pasternak foundation," Applied Mathematical Modelling, vol. 66, pp. 424-439, 2019.

[20] M. Choinière, P. Paultre, and P. Leger, "Influence of soil-structure interaction on seismic demands in shear wall building gravity load frames,” Engineering Structures, vol. 198, 2019.

[21] X. Kang, H. Sun, H. Luo, T. Dai, and R. P. Chen, “A portable bender element-double cone penetration testing equipment for measuring stiffness and shear strength of in-situ soft soil deposits," KSCE Journal of Civil Engineering, vol. 24, no. 12, pp. 3546-3560, 2020.

[22] H. Dong, J. Sun, M. Arif, N. Golsanami, W. Yan, and Y. Zhang, "A novel hybrid method for gas hydrate filling modes identification via digital rock," Marine and Petroleum Geology, vol. $115,2020$.

[23] N. Golsanami, X. Zhang, W. Yan et al., "NMR-based study of the pore types' contribution to the elastic response of the reservoir rock," Energies, vol. 14, no. 5, 2021.

[24] Y. Cai, Z. Xie, J. Wang, P. Wang, and X. Geng, "Reply to the discussion by Mesri and Kane on "New approach of vacuum preloading with booster prefabricated vertical drains (PVDs) to improve deep marine clay strata"," Canadian Geotechnical Journal, vol. 56, no. 12, pp. 2017-2017, 2019.

[25] Y. Ma, T. M. Evans, and D. D. Cortes, "2D DEM analysis of the interactions between bio-inspired geo-probe and soil during inflation-deflation cycles," Granular Matter, vol. 22, no. 1, pp. 1-14, 2020.

[26] G. L. Marschmann, H. Pagel, P. Kügler, and T. Streck, "Equifinality, sloppiness, and emergent structures of mechanistic soil biogeochemical models," Environmental Modelling \& Software, vol. 122, 2019.

[27] Y. Pan, Y. Liu, F. H. Lee, and K. K. Phoon, "Analysis of cement-treated soil slab for deep excavation support-a rational approach," Géotechnique, vol. 69, no. 10, pp. 888-905, 2019.

[28] N. Golsanami, E. Bakhshi, W. Yan et al., "Relationships between the geomechanical parameters and Archie's coefficients of fractured carbonate reservoirs: a new insight," Energy Sources, Part A: Recovery, Utilization, and Environmental Effects, vol. 2020, pp. 1-25, 2020.

[29] Y. Zhao, Y. Zhang, H. Yang, Q. Liu, and G. Tian, "Experimental study on relationship between fracture propagation and pumping parameters under constant pressure injection conditions," Fuel, vol. 307, article 121789, 2021.
[30] Y. Zhao, C. L. Wang, and J. Bi, "Analysis of fractured rock permeability evolution under unloading conditions by the model of elastoplastic contact between rough surfaces," Rock Mechanics and Rock Engineering, vol. 53, no. 12, pp. 57955808, 2020.

[31] Y. Zhao, J. Bi, C. Wang, and P. Liu, "Effect of Unloading Rate on the Mechanical Behavior and Fracture Characteristics of Sandstones Under Complex Triaxial Stress Conditions," Rock Mechanics and Rock Engineering, vol. 54, no. 9, pp. 48514866, 2021.

[32] Y. Wu, X.-Z. Li, Z. Huang, and S. Xue, "Effect of temperature on physical and mechanical and acoustic emission properties of Beishan granite Gansu Province, China," Natural Hazards, vol. 107, no. 2, pp. 1577-1592, 2021.

[33] S. Gong, L. Zhou, Z. Wang, and W. Wang, "Effect of bedding structure on the energy dissipation characteristics of dynamic tensile fracture for water-saturated coal," Geofluids, vol. 2021, Article ID 5592672, 10 pages, 2021.

[34] Y. Wang, Y. Zhang, M. Li, Y. Qi, and T. Ma, “A numerical investigation of the deformation mechanism of a large metro station foundation pit under the influence of hydromechanical processes," Geofluids, vol. 2021, Article ID 5536137, 16 pages, 2021.

[35] W. Hou, H. Wang, L. Yuan, W. Wang, Y. Xue, and Z. Ma, "Experimental research into the effect of gas pressure, particle size and nozzle area on initial gas-release energy during gas desorption," International Journal of Mining Science and Technology, vol. 31, no. 2, pp. 253-263, 2021.

[36] Y. G. Zhang, J. Qiu, Y. Zhang, and Y. Wei, "The adoption of ELM to the prediction of soil liquefaction based on CPT," Natural Hazards, vol. 107, no. 1, pp. 539-549, 2021.

[37] Y. G. Zhang, J. Tang, R. P. Liao et al., "Application of an enhanced BP neural network model with water cycle algorithm on landslide prediction," Environmental Research and Risk Assessment, vol. 35, no. 6, pp. 1273-1291, 2021.

[38] C. Mark, "An updated empirical model for ground control in U.S. multiseam coal mines," International Journal of Mining Science and Technology, vol. 31, no. 2, pp. 163-174, 2021.

[39] Y. Zhang, J. Qiu, Y. Zhang, and Y. Xie, “The adoption of a support vector machine optimized by GWO to the prediction of soil liquefaction," Environmental Earth Sciences, vol. 80, no. 9, pp. 1-9, 2021.

[40] H. Rafezi and F. Hassani, "Drilling signals analysis for tricone bit condition monitoring," International Journal of Mining Science and Technology, vol. 31, no. 2, pp. 187-195, 2021.

[41] Y.-G. Zhang and L. Yang, "A novel dynamic predictive method of water inrush from coal floor based on gated recurrent unit model," Natural Hazards, vol. 105, no. 2, pp. 2027-2043, 2021.

[42] Y.-G. Zhang, J. Tang, Z.-Y. He, J. Tan, and C. Li, “A novel displacement prediction method using gated recurrent unit model with time series analysis in the Erdaohe landslide," Natural Hazards, vol. 105, no. 1, pp. 783-813, 2021.

[43] W. Tang, C. Zhai, J. Xu, Y. Sun, Y. Cong, and Y. Zheng, "The influence of borehole arrangement of soundless cracking demolition agents (SCDAs) on weakening the hard rock," International Journal of Mining Science and Technology, vol. 31, no. 2, pp. 197-207, 2021.

[44] Y.-G. Zhang, Y. Xie, Y. Zhang, J. Qiu, and S. Wu, “The adoption of deep neural network (DNN) to the prediction of soil liquefaction based on shear wave velocity," Bulletin of Engineering Geology and the Environment, vol. 80, no. 6, pp. 5053-5060, 2021. 
[45] Y. Zhou, D. Zhao, B. Li, H. Wang, Q. Tang, and Z. Zhang, "Fatigue damage mechanism and deformation behaviour of granite under ultrahigh-frequency cyclic loading conditions," Rock Mechanics and Rock Engineering, vol. 54, no. 9, pp. 4723-4739, 2021.

[46] X. Liu, S. Song, Y. Tan et al., "Similar simulation study on the deformation and failure of surrounding rock of a large section chamber group under dynamic loading," International Journal of Mining Science and Technology, vol. 31, no. 3, pp. 495-505, 2021.

[47] X. Liu, D. Fan, Y. Tan et al., "New detecting method on the connecting fractured zone above the coal face and a case study," Rock Mechanics and Rock Engineering, vol. 54, no. 8, pp. 4379-4391, 2021.

[48] X. Liu, D. Fan, Y. Tan et al., "Failure evolution and instability mechanism of surrounding rock for close-distance parallel chambers with super-large section in deep coal mines," International Journal of Geomechanics, vol. 21, no. 5, 2021.

[49] R. Kumar, P. K. Mandal, A. Narayan, and A. J. Das, "Evaluation of load transfer mechanism under axial loads in a novel coupler of dual height rock bolts," International Journal of Mining Science and Technology, vol. 31, no. 2, pp. 225-232, 2021.

[50] T. Qiu and Y. Zhang, "Experimental research on the adhesion characteristics of clay to structures with different materials," Geofluids, vol. 2021, Article ID 3794889, 11 pages, 2021.

[51] J. Ma, X. Li, J. Wang et al., "Experimental study on vibration reduction technology of hole-by-hole presplitting blasting," Geofluids, vol. 2021, Article ID 5403969, 10 pages, 2021.

[52] J. Yang, H. Lian, and V. P. Nguyen, "Study of mixed mode I/II cohesive zone models of different rank coals," Engineering Fracture Mechanics, vol. 246, 2021.

[53] J. Yang, H. Lian, and L. Li, "Investigating the effect of confining pressure on fracture toughness of $\mathrm{CO}_{2}$-saturated coals," Engineering Fracture Mechanics, vol. 242, 2021.

[54] J. Wang, T. Zuo, X. Li, Z. Tao, and J. Ma, "Study on the fractal characteristics of the pomegranate biotite schist under impact loading," Geofluids, vol. 2021, Article ID 1570160, 8 pages, 2021. 